Artigos

\title{
Crítica e normatividade \\ Considerações acerca da solidariedade política e do orçamento participativo
}

\author{
Criticism and normativity \\ Considerations about political solidarity and participatory budgeting
}

\author{
Crítica y normatividad \\ Consideraciones sobre la solidaridad política y el \\ presupuesto participativo
}

Henrique Sousa Assai ${ }^{1}$

\begin{abstract}
Resumo: A filosofia política e a filosofia social têm se deparado ultimamente com desafios normativos que exigem cada vez mais esforços para respondê-los. Dentre eles está certamente o vertiginoso processo de despolitização da esfera pública que qual solapa a vida societária. Urge, portanto, sob o ponto de vista da pesquisa crítica, propor respostas para o referido problema. Este artigo pretende explicitar, baseado no pensamento crítico-reflexivo, a ação social de cunho solidário do orçamento participativo como possibilidade de responder ao processo de despolitização da esfera pública. Nesse sentido, o projeto da deliberação orçamentária pode contribuir para a sociedade mediante a ação repolitizadora na esfera pública na medida em que ele se constitui enquanto medium sócio-normativo na sociedade.
\end{abstract}

Palavras-chave: Teoria crítica; Esfera pública; Orçamento participativo.

Abstract: The political philosophy and the social philosophy have recently been confronted with normative challenges that require significant efforts in trying to respond them. Among them one is the vertiginous process of depoliticisation of the public sphere. It undermines the social life. From the point of view of critical research it is necessary to propose answers to this problem. Based on critical and reflexive thinking, this article aims to make explicit the solidarity social action of participatory budgeting as possibility to solve the depoliticisation of public sphere. In this sense, the project of deliberative budgeting can contribute to society through repoliticizing action in the public sphere insofar as it functions as a social-normative medium in the society.

Keywords: Critical theory; Public sphere; Participatory budgeting.

Resumen: La filosofía política y la filosofía social se han enfrentado últimamente con desafíos normativos que exigen cada vez más esfuerzos para responder. Entre ellos ciertamente está el vertiginoso proceso de despolitización de la esfera pública que socava

\footnotetext{
${ }^{1}$ Universidade Federal do Maranhão (Ufma, Imperatriz, MA, Brasil).

autor.dados_biográficos
}

Civitas, Porto Alegre, v. 18, n. 3, p. 718-730, set.-dez. 2018

Este artigo está licenciado sob forma de uma licença Creative Commons Atribuição 4.0 Internacional, que permite uso irrestrito, distribuição e reprodução em qualquer meio, desde que a publicação original seja corretamente citada. https://creativecommons.org/licenses/by/4.0/deed.pt_BR 
la vida societaria. Por lo tanto, es urgente, desde el punto de vista de la investigación crítica, proponer respuestas a dicho problema. Este artículo pretende explicitar, basado en el pensamiento crítico-reflexivo, la acción social de cuño solidario del presupuesto participativo como posibilidad de responder al proceso de despolitización de la esfera pública. En este sentido, el proyecto de la deliberación presupuestaria puede contribuir a la sociedad mediante la acción repolitizadora en la esfera pública en la medida en que se constituye como medium socio-normativo en la sociedad.

Palabras clave: Teoría crítica; Esfera pública; Presupuesto participativo.

\section{Contextualizando a questão}

Um dos desafios normativos da filosofia política assim como da filosofia social precisamente nessa década é articular uma forma de (re)pensar a democracia não só enquanto uma expressão do poder do povo, mas, sobretudo, na perspectiva do problema da admissibilidade temática em estabelecer paradigmas normativos sociopolíticos de cunho pós-convencional que balizem a democracia (Petit; Goodin e Pooge, 2007). No âmago desse cenário, novos problemas emergem do tecido societário (ordem filogênica) ao nível tanto local quanto global. Dentre eles, um dos principais é o processo de despolitização da esfera pública. Porém, ao mesmo tempo, a pesquisa crítica traz à luz novas possibilidades de resposta a eles (Fiala, 2015). O legado da teoria crítica ainda se constitui como um caminho possível para responder a questão da despolitização da esfera pública, na medida em que tanto a própria pesquisa crítica quanto a democracia são convidadas a se reinventarem no sentido de suas autocompreensões crítico-reflexivas como formas de expressão filosóficas de uma determinada governabilidade (Brunkhorst, 2014). Neste texto, despolitização na (da) esfera pública significa a ação disruptiva, mediante os mecanismos ideológicos de poder (Jaeggi, 2008; 2014a; Walzer 2009; Stahl 2014) para com a esfera do "Social" (das Soziale) (Jaeggi e Celikates, 2017) - compreendido fundamentalmente pelas práticas sociais assim como as instituições e relações. Um corolário marcante da despolitização é o desprovimento de bens sociais para um determinado povo. Já a esfera pública passa a ser compreendida como um

espaço público (que) se torna a arena da definição contenciosa acerca do que é o político, isto é, do que pertence à pólis. Sua função principal é trazer para a discussão aberta questões problematizadas pelos movimentos sociais - pelas instituições sociais - permitindo à sociedade como um todo assumir seus dilemas internos, transformando-os em política (Avritzer, 1999). 
Com o intuito de apresentar uma proposta socionormativa à questão da democracia como expressão do poder advindo do povo, pretendo explicitar um elemento copartícipe da urdidura democrática, qual seja, a solidariedade de cunho sociopolítico. A democracia exige ancoradouros para dar legitimidade ao exercício da força democrática a fim de encetar uma via ao processo de politização da esfera pública em um cenário eivado de patologias sociais. Esta solidariedade é concebida no interior de uma esfera pública autorreferente ao estado democrático de direito e se vincula ao que cognomino aqui de orçamento participativo enquanto medium socionormativo, de um Platzhalter (lugar-tenente) democrático. Como forma de explicitar metodologicamente tal "jogo" político-democrático e, enquanto uma linha de investigação crítica na filosofia política e até mesmo na filosofia social, proponho primeiramente considerar a ideia de esfera pública - retomando especificamente a compreensão habermasiana presente em Ach Europa (2008) - como um espaço orientado à normatividade e que possui uma força e um telos emancipador (1). Em um segundo momento, pretendo vincular a esfera pública com o princípio da solidariedade, seguindo a interpretação de Rahel Jaeggi da solidariedade enquanto procedimento não apenas cívico, mas, sobretudo, político e social, e que oferece concretamente alternativas orientadas à práxis (2). Por fim, tomando por referência que a solidariedade sociopolítica se constitui como fundamento para a ação social na efetivação do orçamento participativo, abordarei brevemente o projeto sociopolítico e solidário do orçamento participativo ou da deliberação orçamentária enquanto uma forma de vida social e política (3). A tese do texto é que esta forma de deliberação se candidata a ser um possível medium socionormativo na democracia, que tem como autorreferência seu próprio povo, constituindo-se, assim, como expressão objetiva na forma de governo no interior do estado democrático de direito, no qual busca garantir e efetivar direitos (bens sociais, políticos, civis e econômicos).

\section{Democracia e esfera pública: diagnóstico e desafio socionormativo}

Quando Habermas definiu a esfera pública como muito importante para uma concepção societária democrática, ele o fez inicialmente caracterizando-a enquanto contexto sociohistórico, até chegar aos implexos normativoinstitucionais presentes na sociedade (Habermas 1997; 1995a; Lubenow, 2007). Assim, ao caracterizar a esfera pública como elemento fundamental na urdidura teórica de sua concepção de sociedade, Habermas considera que uma determinada forma democrática exige uma esfera pública (política) capaz de 
não só fazer eco aos anseios do povo (Habermas, 2008) - sendo um sistema de comunicação intermediário entre as organizações e a sociedade civil mas, sobretudo, de acolher tais ecos (na linguagem honnethiana seriam as patologias sociais) sob um ponto de vista crítico-normativo e incluí-los numa agenda programática emancipatória (práxis) da sociedade (Stahl, 2014).

No tocante à definição de esfera pública em Ach Europa, o texto parte, por um lado, da diferenciação conceitual entre "sociedade e "sociedade civil" e, por outro, entre "esfera pública" e "esfera pública política”. Essa diferenciação é decisiva tanto na obra habermasiana quanto para a presente pesquisa. $\mathrm{Na}$ abordagem habermasiana, esta diferença advém de uma releitura conceitual e estrutural não só da esfera pública, mas também da sociedade, sendo esta última um dos elementos estruturantes da ideia básica de Habermas a respeito do mundo da vida. Não poderei me ater nesses pormenores aqui, mas menciono essa questão e apresento a seguir uma curta explicitação desses conceitos.

De forma breve, o conceito de sociedade de Habermas está explicitado em Theorie des Kommunikativen Handelns, onde o autor a definiu enquanto "os ordenamentos legítimos que regulam aos participantes da comunicação sua pertença aos grupos sociais e, com isso, asseguram a solidariedade" (Habermas, 1995a). Tal entendimento foi retomado com os mesmos contornos nocionais em Vorstudien und Ergänzungen zur Theorie des Kommunikativen Handelns (Habermas, 1995b). Porém, em Fakzität und Geltung (1997) houve uma glosa ao conceito de sociedade. Nesta obra foi agregado o termo "civil" a sociedade, sugerindo ao leitor que a noção seminal deste conceito ficou mais próxima de uma abordagem socionormativa, mais precisamente com a aproximação da ideia de esfera pública com o aparato institucional da sociedade civil. Segundo o autor, "a sociedade civil compõe-se de movimentos, organizações e associações, os quais captam os ecos dos problemas sociais que ressoam nas esferas privadas, condensam-nos e os transmitem, a seguir, para a esfera pública política” (Habermas, 1997). Já a esfera pública é descrita como:

um fenômeno social elementar do mesmo modo que a ação, o ator, o grupo ou a coletividade [...], a esfera pública não pode ser entendida como uma instituição, nem como uma organização, pois ela não constitui uma estrutura normativa capaz de diferenciar entre competências e papeis [...]. A esfera pública pode ser descrita como uma rede adequada para a comunicação de conteúdos, tomadas de posição e opiniões [...] (Habermas, 1997, p. 92).

Mas em Ach Europa Habermas acrescenta à esfera pública o termo “política”. Não é só mais uma glosa em seu repertório conceitual acerca da 
esfera pública. Este acréscimo atesta uma tentativa de vincular a ideia de esfera pública com a esfera sociopolítica e normativa. Habermas entende a esfera pública como "por um lado, um sistema de comunicação intermediário entre as orientações (deliberações) organizadas formalmente e as negociações; por outro, os eventos e as conversações informais no âmbito da sociedade civil do sistema político" (Habemas, 2008).

Só que para Habermas permanece clara a tarefa constitutiva da esfera pública política em ser um medium que filtra e controla tudo aquilo que é produzido pela comunicação política. Mas ele se dá conta que a esfera pública política necessita, sob o ponto de vista racional, da legitimidade no próprio processo democrático. Para isso ela deve sustentar e orientar pontos de vista normativos. E é justamente aqui que o modelo deliberativo de democracia entra em cena. No entanto, para que tal normatividade se efetive é preciso que a sociedade civil traduza algumas referências empíricas capazes de aglutinarem os discursos (ação comunicativa) assim como as decisões legiferantes da esfera civil. Nesse texto Habermas ainda se remete, sob o ponto de vista das evidências empíricas, ao quadro categorial da comunicação política e, mais especificamente, da gênese estatal do sistema político como exemplo conceitual da esfera pública que, no seu entendimento, se faz presente tanto no sistema político quanto na sociedade civil (Habermas, 2008). Essa articulação dual traduz, por assim dizer, as categoriais nocionais básicas de sua teoria social (mundo da vida e sistema) e também nos permitem pensar que, mais notadamente em Ach Europa, na ideia de esfera pública política emerge o pressuposto geopolítico do "centro e periferia" tanto quanto as opiniões públicas como corolário remissivo à esfera pública política. Em suas palavras: "[...] as opiniões públicas refletidas resultam do círculo comunicativo entre centro e periferia - enquanto produto da esfera pública" (Habermas, 2008).

Sob o aspecto da esfera pública política, Habermas alude às evidências empíricas inseridas numa perspectiva modal da (na) esfera pública política - ainda considerando os inputs e outputs. Porém, ele não as submete a uma posição que se constitua enquanto fio condutor à práxis. Parece que a relação estabelecida entre as categorias internas e subjacentes à arena da comunicação política não se perfazem como medium para uma normatividade, cuja compreensão mais estrita no interior da pesquisa crítica remete à orientação ao telos da emancipação. O modelo deliberativo, nesse caso, parece funcionar "apenas" dentro de um esquema formal-categorial de uma esfera pública política compreendida no interior do conceito de poder comunicativo e estando circunscrita a sua teoria do agir comunicativo. Isto poderia comprometer a vinculação entre uma proposta de pensamento com a práxis. Em sua 
abordagem sobre o poder é possível perceber que Habermas se dá conta disso. Poder não é entendido apenas sob o "manto" da comunicação perante o quadro teórico de cunho político, mas considerado adjacente à ideia de esfera pública política como poder político, social, econômico e midiático (Habermas, 2008, p. 173-191). Tal tipologia do poder parece sugerir uma orientação emancipatória na medida em que está em jogo, por exemplo, o poder social e econômico e não apenas o substrato formal-tipológico de sua concepção de esfera pública. Para Habermas, o poder político diz respeito ao processo de legitimação e justificação do estado constitucional democrático, que se orienta basicamente pelos processos decisionais de ordem política. Já o poder social trata da ordem estatal de uma sociedade estratificada, enquanto o poder econômico baseia-se nas formas de poder do sistema capitalista e tal ideia retoma a construção teórica social do conceito de sistema, cujo ancoramento se situa no quadro de maior referência de sua teoria da sociedade (mundo da vida e sistema). Por fim, o poder da mídia se fundamenta no saber tecnológico e na infraestrutura da comunicação de massa. Mais tarde Habermas salientaria mais especificamente uma "fenomenologia" do poder tecnocrático enquanto força sistêmica na ação política (Habermas, 2013).

Habermas, no entanto, tende a reconhecer que, sob o ponto de vista da comunicação política, ainda há dificuldades no tocante à sociedade civil em participar junto ao processo de formação da opinião pública e da vontade política. Ele chamou de participação autônoma esse processo de desacoplamento da sociedade civil perante as formas de poder existentes na sociedade ocasionando as patologias da comunicação política (Habermas, 1997). Tais mecanismos disruptivos (patologias na linguagem habermasiana e honnethiana) ocorrem principalmente em virtude da relação descontínua e "alérgica" entre o processo de institucionalização (assim como sua estrutura funcional) na sociedade (midiática principalmente) e as expectativas normativas com pretensões emancipatórias advindas do modelo deliberativo. Nesse caso, parece que Habermas se dá conta de que a questão acerca da esfera institucional concebida como possibilidade de mediação normativa não esteja apenas circunscrita a uma compreensão pragmático-semântica e comunicativa, mas, sobretudo, normativa, no intuito de se conceber a instituição social como medium à emancipação. Nesse sentido, a falta de um ancoramento institucional emancipatório (défice socioinstitucional) gera uma lacuna normativa na abordagem social habermasiana, o que também remeteria a um problema maior no próprio círculo frankfurtiano (Allen, 2016). Assim, o problema quanto ao défice institucional na esfera pública política (Lubenow, 2010; 2013) permanece como elemento heurístico de pesquisa no interior da 
abordagem crítica, fazendo com que a questão participativa da formação da opinião política torne-se decisiva numa análise que leve em conta a colonização da esfera pública. Tal questão repousa na tratativa relativa à autocompreensão do processo solapador pelo qual passa a esfera pública política.

Em Ach Europa Habermas permanece fiel ao diagnóstico de que o imperativo sistêmico-econômico se constitui como uma forma de paralisia da sociedade civil e que isso gera uma forma específica de colonização da esfera pública (Habermas, 2008). Por outro lado, as expectativas normativas e de pretensão emancipatórias são continuamente latentes e eclodem na sociedade civil enredando o argumento de que "apenas" ficar circunscrito ao modelo comunicativo não permite postular que tais expectativas sejam colocadas num patamar de resolução de problemas, onde seja possível se conceber uma esfera pública política endereçada à esfera socionormativa e emancipatória (Assai, 2015a; 2015b). Diferente do "diretivo" enredamento comunicativo às questões sociais, em Fakzität und Geltung Habermas tenta aproximar a esfera pública dos processos institucionais de cunho normativo. Mas ainda assim ele não logra êxito na medida em que não explicita "como" pensar as ações gestadas na esfera pública em ações institucionais enquanto mediações socionormativas e emancipatórias (Avritzer, 1999), já que a esfera pública apenas filtra os conteúdos oriundos da comunicação política. Essa compreensão "formal" de esfera pública, ainda que política, não preenche os requisitos do "espírito" de um programa crítico-normativo, cujo repto se fundamenta, em última instância, nos processos emancipatórios. Sendo assim, penso que seja preciso migrar para outra proposta: creio que a colaboração socionormativa de Rahel Jaeggi (Jaeggi e Loick 2014; Jaeggi e Wesche, 2013) permita não apenas pensar no "Social", mas, sobretudo, no interior dessa mesma esfera, postular caminhos de modo solidário e institucional capazes de resolver as patologias sociais.

\section{Solidariedade como potencialidade normativa para a práxis social}

$\mathrm{Na}$ literatura hodierna, e mais especificamente na filosofia política, há inúmeras tentativas em definir o que é a solidariedade (Scholz, 2008). Entretanto, sob a perspectiva da filosofia social, recepcionarei aqui unicamente a ideia básica de solidariedade enquanto possibilidade socionormativa orientada à práxis (Jaeggi, 2001). Tal orientação possibilita uma abordagem social vinculada ao aporte institucional-normativo e emancipatório capaz de responder aos desafios despolitizadores da esfera pública.

No esteio da gênese constitutiva do conceito de solidariedade, Jaeggi (2001, p. 288) evoca a etimologia latina, vinculando-a a uma abordagem 
histórica e ao mesmo tempo recepcionando a contribuição durkheimiana a respeito. Mas o aparato descritivo no qual Jaeggi se apoia prevê dificuldades de ordem teórica que ela mesma indica: a questão do afeto enquanto pretenso vínculo solidário, a distinção entre solidariedade e amizade e a diferença entre lealdade e demais formas de coalisão. O resultado da pesquisa de Jaeggi é estabelecer que a solidariedade se fundamenta numa forma cooperativa de ação que se deslinda em duas maneiras: ação cooperativa instrumental e ação cooperativa não-instrumental. Esta última remete às formas de vida que pressupõe a ação de caráter ético (cf. Jaeggi, 2014).

Para a cooperação instrumental, a questão basilar repousa no argumento do "puro meio para se conseguir um fim individual". Essa concepção se vincula a uma determinada forma egológica de ação, não promovendo, portanto, uma perspectiva intersubjetiva de ação social ou de cooperação (ação) solidária. Nesse tipo de ação há uma maneira "egoisticamente articulada" de se pensar e agir, não se constituindo, portanto, em um valor em si mesmo (Jaeggi, 2001, p.293). Nesse artigo, Jaeggi não discorre com vagar a respeito da dimensão axiológica propriamente dita. De todo modo, o modelo cooperativo instrumental não permite pensar o "Social" vinculado à esfera institucionalemancipatória.

Contrariamente ao agir cooperativo instrumental, Jaeggi apresenta a ação cooperativa não-instrumental (non-instrumental cooperation), onde a base de argumentação não é o objetivo puramente arbitrário de cunho subjetivista, mas um interesse construído coletivamente, embora a esfera subjetiva seja pressuposta. Assim, fixa-se o jargão "o meu objetivo só é interesse no interesse dos outros" e tal pressuposto admite a ideia fundamental da construção comum enquanto projeto social. Jaeggi chamou de "common goals" a edificação dessa maneira de se pensar e agir em comum, na qual o agir solidário é concebido como um "valor fundamental" (Jaeggi, 2001, p. 295). Perante o pressuposto básico do "Social", o conceito de cooperação não-instrumental permite enredar não apenas a ideia axiológica de uma ação social cooperativa, mas, sobretudo, lidar com a "indiferença" social. Por conseguinte, parece feliz o título de seu artigo - Solidarity and indifference - no qual ela tece uma reflexão a respeito da solidariedade cuja orientação teleológica se dá para a "vida ética". Sim! Uma forma de vida tal que seja capaz de minimizar as indiferenças do mundo egocêntrico, fruto do modelo cooperativo não-instrumental. Essa abordagem de uma "solidariedade que faz a diferença" permite pensar propostas sociais cuja orientação fundamental seja minimizar essa "indiferença" social. Ademais, permite postular uma forma de vida na qual se efetive o "Social". Nessa perspectiva, as instituições sociais, como um dos elementos 
constitutivos da esfera do "Social", podem fazer "essa diferença" no tocante à efetivação dos bens sociais e, nesse caso, apresentar propostas resolutivas de cunho democrático-participativo, aos problemas advindos do processo de despolitização da esfera pública.

No intuito de explicitar de que maneira essa coparticipação públicopolítica é possível na urdidura social no contexto de um estado democrático de direito, delinearei, a seguir, a ideia fundamental do orçamento participativo pensado a partir dos pressupostos de uma filosofia social nos quais são levados a sério os potenciais emancipatórios existentes na sociedade. Dessa forma, a deliberação orçamentária candidata-se como essa potencialidade de constituição (construção) socionormativa, pois esse modelo deliberativoparticipativo se estabelece enquanto medium social e normativo. Na base de sua construção principiológica se assenta uma ideia institucional orientada à práxis no intuito de auxiliar o entendimento e a tomada de posição sobre as deficiências nas condições sociais da autorrealização do sujeito e da sociedade ao tentar buscar respostas, por exemplo, para o revigoramento politizador da esfera pública.

\section{Orçamento Participativo: emancipação e forma de vida sociopolítica e solidária}

Pensar o orçamento participativo (ou a deliberação orçamentária) como uma forma de vida político-solidária na qual se autocompreende uma forma específica de ação social (solidariedade) é postular duas formulações centrais. A primeira, de que a indicação preliminar de um dos sinais de despolitização da esfera pública é a contínua permanência de mecanismos ideológicos disruptivos em uma determinada sociedade (Jaeggi e Celikates, 2017). A segunda, corolária da anterior, é que a despolitização é um óbice para a prática de políticas públicas promotoras de acesso aos bens sociais.

Para Jaeggi, uma forma de vida é uma modalidade de coexistência entre pessoas onde suas práticas sociais são partilhadas intersubjetivamente. Formas de vida são também “ordenamentos cooperativos sociais que se baseiam nas práticas regulares. As formas de vida são delimitadas (abgegrenzt) perante a possibilidade de um desarranjo (Unordnung) e se distinguem, pelo menos da perspectiva interna dos participantes, através de certa expectativa de cooperação" (Jaeggi, 2014, p. 77-78).

Retomando rapidamente o argumento de Jaeggi a respeito da "solidariedade como empoderamento" (Jaeggi, 2001, p.300), creio que o dispositivo institucional da deliberação orçamentária pode estabelecer a força do agir solidário como resposta ao processo de indiferenciação 
social, cuja expressão é, dentre tantas, o não provimento dos bens sociais ao povo de uma determinada sociedade. O teor "empoderativo" do agir solidário da deliberação orçamentária ocorre na medida em que ela busca propor, tendo presente o "espírito de sua autocompreensão", um modelo de participação de todos os envolvidos no processo (Sánchez, 2002) sendo, nesse caso, remissivo à forma do agir cooperativo não-instrumental descrita por Jaeggi.

O orçamento participativo não é só compreendido enquanto uma forma de vida social, mas também como uma instituição social, entendida como uma "estrutura circunscrita à construção da práxis social assim como também voltada para as complexas disposições das práticas e normas de uma determinada sociedade" (Jaeggi, 2009, p. 533). Sendo uma instituição social, a deliberação orçamentária também passa a ser entendida como uma instituição participativa, pois diz respeito às "formas diferenciadas de incorporação de cidadãos e associações da sociedade civil na deliberação sobre políticas" (Avritzer, 2008).

Partindo do pressuposto de que o orçamento participativo é uma instituição social, concebida em sua gênese constitutiva como uma forma de vida sociopolítica e solidária, então resta retornar à questão central do texto: em que medida se pode pensar o orçamento participativo como medium socionormativo capaz de propor soluções aos problemas sociais (patologias sociais na linguagem honnethiana) advindos, sobretudo, do solapador processo de despolitização da esfera pública?

A ação solidária, no âmago da pesquisa filosófica social, pode ser considerada uma possibilidade de resposta para as patologias sociais (Jaeggi e Celikates, 2017, p. 27), dentre elas o "esgotamento" de ordem política da (e na) esfera pública. Sob o esteio crítico ideológico, o Orçamento Participativo, ao assumir por exemplo o procedimento da seleção das prioridades a serem efetivadas socialmente em um determinado local, auxilia no repto em politizar a esfera pública, pois com base numa ação ética de caráter público (Audard, 2006, p. 150) explicita as relações de exploração e de poder subjacentes aos mecanismos ideológicos que obliteram o provimento de bens sociais para a população por meio de políticas públicas (Helfer, 2012).

Do ponto de vista da pesquisa crítica, o desafio do orçamento participativo é se estabelecer como "análise e reflexão crítica" com pretensão resolutiva das patologias sociais nos termos que Jaeggi e Celikates (2017, p. 117) as definem onde. O vínculo disruptivo ocorre justamente na "indiferença" para com o "Social" e que aqui leva a alcunha de "despolitização da esfera pública". No Orçamento Participativo emerge uma normatividade latente do que Jaeggi 
(2014, p. 142-199) designa de forma de vida social, solidária e emancipatória. Por um lado, uma norma social pressupõe um determinado padrão de procedimento e de regra(s) no sentido de estruturar a vida de uma maneira geral (Jaeggi, 2014, p. 144); por outro, ao se estabelecer estruturalmente no tecido social na admissibilidade da existência da norma social como condição ao funcionamento da práxis social, o orçamento participativo age socialmente de maneira cooperativa "não-instrumental". Nesse sentido, a solidariedade presente na deliberação orçamentária se cristaliza enquanto instituição promotora ao bem-estar, uma vez que permanece na luta ao acesso aos bens sociais, fazendo com que sua pretensão normativa e emancipatória esteja continuamente num patamar "paroquiano" (Agamben, 2010) de autoentendimento e, que por isso mesmo, sua atitude voltada à práxis é exigida enquanto houver sinais da "indiferença" para com a solidariedade ao "Social".

\section{Referências}

AGAMBEN, Giorgio. La chiesa e il regno. Roma: Nottetempo, 2010.

ALLEN, Amy. The end of progress: decolonizing the normative foundations of critical theory. New York: Columbia University Press, $2016<10.7312 /$ alle17324>.

ASSAI, José Henrique Sousa. De "Leiden an Unbestimmtheit" à "Erfolg an Bestimmtheit": um caminho possível da reconstrução normativa honnethiana? Griot, v. 11, n. 1, p. 226-244, 2015a.

ASSAI, José Henrique Sousa. Solidariedade como pressuposto de uma ontologia social: investigação possível para uma Teoria Crítica? In: Agemir Bavaresco; Francisco Jozivan Lima; José Henrique Sousa Assai (orgs.). Estudos de filosofia social e política: justiça e reconhecimento. Porto Alegre: Editora Fi, 2015b. p. 153-189.

AUDARD, Catherine. Cidadania e democracia deliberativa. Porto Alegre: Edipucrs, 2006.

AVRITZER, Leonardo. Teoria democrática, esfera pública e participação local. Sociologias, v. 1, n. 2, p. 18-43, 1999.

AVRITZER, Leonardo. Instituições participativas e desenho institucional: algumas considerações sobre a variação da participação no Brasil democrático. Opinião Pública, v. 14, n. 1, p. 43-64, $2008<10.1590 /$ S0104-62762008000100002>.

BRUNKHORST, Hauke. Critical theory of legal revolutions: evolutionary perspectives. New York: Bloomsbury Publishing, 2014.

FIALA, Andrew. The Bloomsbury companion to political philosophy. New York: Bloomsbury Publishing Ple., 2015.

HABERMAS, Jürgen. Theorie des kommunikativen Handelns: zur Kritik der funktionalistischen Vernunft. Frankfurt am Main: Suhrkamp, 1995a. 
HABERMAS, Jürgen. Erläuterungen zum Begriff des kommunikativen Handelns. In: Jürgen Habermas. Vorstudien und Ergänzungen zur Theorie des kommunikativen Handelns. Frankfurt am Main: Suhrkamp, 1995b. p. 571-606.

HABERMAS, Jürgen. Direito e democracia: entre facticidade e validade. Rio de Janeiro: Tempo Brasileiro, 1997. 2 v.

HABERMAS, Jürgen. Ach, Europa: kleine politische Schriften. v. 11. Frankfurt am Main: Suhrkamp, 2008.

HABERMAS, Jürgen. Im Sog der Technokratie: kleine politische Schriften. v. 14. Berlin: Suhrkamp, 2013.

HELFER, Inácio. Os bens sociais são sempre bens convergentes? Trans/Form/Ação, v. 35, n. 2, p. 163-186, $2012<10.1590 /$ S0101-31732012000200009>.

JAEGGI, Rahel. Solidarity and indifference. In: Ruud ter Meulen; Will Arts; Ruud Muffels (orgs.). Solidarity in health and social care in Europa. Dordrecht: Springer, 2001. p. 287-308.

JAEGGI, Rahel. Repensando a ideologia. Civitas, v. 8, n. 1, p. 137-165, 2008 $<10.15448 / 1984-7289.2008 .1 .4326>$.

JAEGGI, Rahel. Was ist eine (gute) Institution? In: Rainer Forst; Martin Hartmann; Rahel Jaeggi; Martin Saar (orgs.). Sozialphilosophie und Kritik. Frankfurt am Main: Suhrkamp, 2009. p. 528-544.

JAEGGI, Rahel. Kritik von Lebensformen. 2. ed. Berlin: Suhrkamp, 2014.

JAEGGI, Rahel; LOICK, Daniel (orgs.). Nach Marx: Philosophie, Kritik, Praxis. 2. ed. Berlin: Suhrkamp, 2014.

JAEGGI, Rahel; WESCHE, Tilo (orgs.). Was ist Kritik? 3. ed. Frankfurt am Main: Suhrkamp, 2013.

JAEGGI, Rahel; CELIKATES, Robin. Sozialphilosophie: eine Einführung. München: C. H. Beck, 2017.

LUBENOW, Jorge Adriano. Esfera pública e democracia deliberativa em Habermas: modelo teórico e discursos práticos. Kriterion, v. 51, n. 121, p. 227-258, 2010 $<10.1590 /$ S0100-512X2010000100012>.

LUBENOW, Jorge Adriano. O que há de político na Teoria da Ação Comunicativa? Sobre o déficit de institucionalização em Jürgen Habermas. Philósophos, v. 18, n. 1, p. 157-190, 2013.

PETTIT, Phillip Pettit; GOODIN, Robert; POGGE, Thomas. A companion to contemporary political philosophy. Oxford: Blackwell, 2007.

SÁNCHEZ, Félix. Orçamento Participativo: teoria e prática. São Paulo: Cortez, 2002.

SCHOLZ, Sally J. Political solidarity. Pennsylvania: University Press, 2008.

STAHL, Titus. Ideologiekritik als Kritik sozialer Praktiken. In: Rahel Jaeggi; Daniel Loick (orgs.). Nach Marx: Philosophie, Kritik, Praxis. 2. ed. Berlin: Suhrkamp, 2014. p. 228-254. 
TAYLOR, Charles. Argumentos filosóficos. São Paulo: Loyola, 2000.

WALZER, Michael. Gesellschaftskritik und Gesellschaftstheorie. In: Rainer Forst; Martin Hartmann; Rahel Jaeggi; Martin Saar (orgs.). Sozialphilosophie und Kritik. Frankfurt am Main: Suhrkamp, 2009. p. 588-607.

Recebido em: 3 mar. 2017

Aprovado em: 15 set. 2017

Autor correspondente:

Henrique Sousa Assai

Universidade Federal do Maranhão

Rua Urbano Santos, s/n

65900-410 Imperatriz, MA, Brasil

HENRIQUE SOUSA ASSAI <rickmaslz@msn.com>

Doutor em Filosofia pela Pontifícia Universidade Católica do Rio Grande do Sul (Pucrs, Porto Alegre, RS, Brasil), professor na Universidade Federal do Maranhão (Ufma) em Imperatriz, MA, Brasil. ORCID: https://orcid.org/0000-0002-5846-4997 